\title{
PENGARUH KEPEMIMPINAN TRANSFORMASIONAL DAN KEPUASAN KERJA TERHADAP ORGANIZATIONAL CITIZENSHIP BEHAVIOR PADA ISLAMIC BOARDING SCHOOL TINGKAT SMA DI YOGYAKARTA
}

\author{
Arief Darmawan, S.E., MM., ${ }^{1 *}$, Maisaroh, S.E., MSi., ${ }^{2}$. \\ 1,2 Program Diploma III Ekonomi, Universitas Islam Indonesia \\ *Korespondensi: darmawan@uii.ac.id
}

\begin{abstract}
This research examine the influence of transformational leadership and job satisfaction on organizational citizenship behavior, relationship between variables and how transformational leadership and organizational citizenship behavior are applicated to the school at Islamic boarding high school in Yogyakarta. This research examine four hypothesis, it were there is positive influence between variable of transformational leadership toward organizational citizenship behavior; there is positive influence between job satisfaction variable with organizational citizenship behavior; there is positive influence between variable of transformational leadership and job satisfaction; between transformational leadership variable to organizational citizenship behavior with intervening variable of job satisfaction. Using SPSS 17, analyzing data through several stages of analysis, first, requirements analysis test, path coefficient test, and significance test of path coefficient analysis. The result of path analysis shows that simultaneously independent variables of transformational leadership and job satisfaction have influence on the organization citizenship behavior ( $f$-value 23.455 with a significance level of 0.00 ). The model equation is X2 = 0.681 X1 $+\rho x 2 \varepsilon$ and $Y=0.309 X 1+0.346 X 2+\rho y \varepsilon$. In addition simultaneously from the two models, it can be concluded that there is moderating influence of job satisfaction variable in relationship between transformational leadership variable and organization citizenship behavior variable. Partially, transformational leadership variables and job satisfaction also have a direct influence on the organization citizenship behavior ( $t$-value 2,289 and 2, 582 with significance level of 0.005 and 0.012). Calculation of coefficient determination indicate that transformational leadership and job satisfaction have influence on citizenship behavior organization as 36, 1\%, while the other are influenced by other variable not examined.
\end{abstract}

Keywords: Transformational Leadership, Job Satisfaction, Organizational Citizenship Behavior.

\begin{abstract}
ABSTRAK
Penelitian ini menguji pengaruh kepemimpinan transformasional dan kepuasan kerja terhadap organizational citizenship behavior, melihat pola penerapan kepemimpinan transformasional dan pola penerapan organizational citizenship behavior pada lembaga sekolah pada Islamic boarding school setingkat SMA di Yogyakarta. Penelitian ini menguji empat hipotesis,yaitu terdapat pengaruh positif antara variabel kepemimpinan transformasional terhadap organizational citizenship behavior, terdapat pengaruh positif antara variabel kepuasan kerja dengan organizational citizenship behavior, terdapat pengaruh positif antara variabel kepemimpinan transformasional dan kepuasan kerja, dan terakhir, terdapat pengaruh antara variabel kepemimpinan transformasional terhadap organizational citizenship behavior dengan intervening variabel kepuasan kerja. Analisis data dilakukan melalui tahapan uji persyaratan analisis, uji koefisien jalur, dan uji keberartian koefisien jalur menggunakan SPSS 17. Hasil uji analisis jalur menunjukkan bahwa secara simultan variabel independen kepemimpinan transformasional dan kepuasan kerja memiliki pengaruh terhadap variabel dependen organization citizenship behavior (F-hitung 23,455; taraf signifikansi 0,00). Persamaan model yang dihasilkan adalah $\mathrm{X} 2=0,681 \mathrm{X} 1+\rho_{\mathrm{x} 2 \varepsilon}$ dan $\mathrm{Y}=0,309 \mathrm{X} 1+0,346 \mathrm{X} 2+\rho_{\mathrm{y \varepsilon}}$. Selain pengaruh simultan, dari dua model tersebut dapat disimpulkan adanya pengaruh moderating variabel kepuasan kerja dalam hubungan antara variabel kepemimpinan transformasional dan variabel organization citizenship behavior. Secara parsial, variabel kepemimpinan transformasional dan kepuasan kerja juga memiliki pengaruh langsung terhadap organization citizenship behavior (T-hitung 2,289 dan 2,582 dengan taraf signifikansi 0,005 dan 0,012). Perhitungan koefisien determinasi menunjukkan bahwa variabel kepemimpinan transformasional dan kepuasan kerja mempengaruhi variabel organization citizenship behavior sebesar $36,1 \%$, sedang sisanya dipengaruhi oleh variabel lain yang tidak diteliti.
\end{abstract}

Kata Kunci : Kepemimpinan Transformasional, Kepuasan Kerja, Organizational Citizenship Behavior. 


\section{PENDAHULUAN}

Pendidikan memberikan sumbangan yang signifikan bagi sebuah bangsa. Sehingga berinvestasi dalam bidang pendidikan menjadi penting dilakukan oleh suatu bangsa. Tidak bisa dipungkiri bahwa dalam menghadapi persaingan global yang semakin ketat, maka investasi dalam bidang pendidikan ini akan bisa meningkatkan kualitas SDM suatu bangsa. Dengan peningkatan kualitas SDM, posisi tawar SDM suatu negara akan meningkat, mudah diterima pasar, dan akan mampu menekan pengangguran. Dengan pengangguran yang rendah, maka laju ekonomi suatu negara akan meningkat pula. Begitu pentingnya peran SDM yang berkualitas ini, maka negaranegara yang sudah maju pasti mengalokasikan dana anggaran untuk pendidikan dalam jumlah yang besar.

Saat ini, negara-negara berkembang juga sudah mulai sadar akan pentingnya berinvestasi dalam bidang pendidikan dalam rangka meningkatkan kualitas SDM nya. Khusus untuk Indonesia, semangat untuk mengembangkan program-program pendidikan sebenarnya sudah mulai ada sejak Indonesia merdeka. Hal ini terbukti dari amanah UUD 45 dan amanah UU yang dibuat, dimana dalam amanah tersebut disebutkan bahwa setiap warga negara Indonesia berhak mendapatkan pendidikan yang layak. Dalam rangka mewujudkan amanah tersebut, pemerintah dari masa ke masa juga telah merancang dan melaksanakan program pendidikan berkesinambungan. Kesempatan sekolah juga semakin terbuka luas bagi seluruh rakyat indonesia dengan program wajib belajar 9 tahun, maupun program beasiswa yang ditawarkan pemerintah.

Dari kondisi persaingan bisnis pendidikan yang semakin ketat, sekolah yang ingin menang dalam persaingan, ditantang untuk memberikan kualitas yang terbaik bagi pelanggannya dalam hal ini adalah siswa-siswa yang belajar. Ada dua pihak yang terkait dengan proses pemberian layanan terbaik ini, yaitu karyawan yang memberikan pelayanan administratif dan pelayanan penyediaan fasilitas belajar mengajar, dan guru sebagai tenaga pendidik yang langsung menggawangi proses belajar mengajar. Agar bangunan kualitas pelayanan tersebut menjadi solid dan kokoh, baik pihak karyawan maupun guru harus bahu membahu dan mengembangkan kerja sama tim yang baik sehingga pelayanan kualitas tersebut dapat terwujud dan mampu memberikan kepuasan kepada siswa yang sedang belajar.

Efektifitas kinerja guru dari waktu ke waktu masih menjadi problem yang belum terselesaikan. Harian Kompas, setidaknya pernah menulis bahwa efektifitas kinerja guru yang sudah tersertifikasi masih rendah (Oktober 2009). Bahkan program sertifikasi guru yang dilaksanakan pemerintah, diawal kemunculan program masih belum memberikan pengaruh yang signifikan dalam memperbaiki efektifitas kinerja guru. Pada perjalanannya program sertifikasi guru baru memberikan pengaruh positif pada efektifitas kinerja guru karena diperkuat oleh faktor eksternal, yaitu semakin membaiknya hubungan antar rekan kerja guru (Ulfa, 2012). Faktor 
hubungan baik ini semakin terjalin baik, karena ada perasaan senasib bahwa mereka harus mempertahankan sertifikasi yang sudah mereka peroleh. Perasaan senasib ini yang menyadarkan mereka harus saling bahu membahu meningkatkan kinerja mereka. Dalam prosesnya kemudian muncul sikap membantu temannya dalam menyiapkan tugas mengajar, penelitian, dan aktifitas lain. Dan kesadarn saling membantu tersebut muncul atas kesadaran diri dan bukan sekedar tanggung jawab atas pekerjaan.

Sejalan dengan hasil penelitian Siti Asiah (2016), menjelaskan bahwa efektifitas kinerja guru salah satunya dipengaruhi oleh hubungan antar manusia tanpa direkayasa diluar tugas yang sudah dibebankan. Kondisi ini yang kemudian disebut sebagai perilaku organizational citizenship behavior. Meskipun perilaku organizational citizenship behavior ini ditengarai menjadi salah satu faktor penentu keefektikan kinerja guru, akan tetapi masih banyak lembaga sekolah yang gurugurunya belum menerapkan perilaku tersebut. Hasil pra survey lapangan yang dilakukan peneliti pada tahun 2014, menunjukkan bahwa di Jakarta masih jarang guru-guru dan tenaga non kependidikan yang menerapkan perilaku organizational citizenship behavior ini. Guru dan tenaga non kependidikan sebagian besar masih bekerja dalam area tugas yang menjadi tanggung jawabnya saja.

Organization citizenship behavior (OCB) adalah suatu sikap perilaku karyawan yang dilakukan dengan sukarela, tulus, senang hati tanpa harus diperintah dan dikendalikan oleh perusahaan dalam memberikan pelayanan dengan baik (Organ et al., 2006). Perilaku dan sikap ini yang oleh banyak ahli ditengarai akan menjadi modal bagi keberhasilan sebuah organisasi dalam membangun tim kerja yang baik.

Sebenarnya, ada banyak faktor yang bisa mempengaruhi Organization citizenship behavior (OCB). Selain faktor individu karyawan itu sendiri, kepuasan kerja dan gaya kepemimpinan yang diterapkan oleh pimpinan juga bisa mempengaruhi Organization citizenship behavior (OCB), Seperti kita ketahui ada banyak gaya kepemimpinan yang biasa dilakukan oleh seorang pemimpin dalam memimpin sebuah organisasi. Efektifitas kepemimpinan yang dilakukan menjadi salah satu faktor penentu keberhasilan organisasi. Dalam konteks Organization citizenship behavior (OCB), kepemimpinan transformasional akan mendorong tumbuhnya perilaku saling menolong dan membantu secara sukarela diantara karyawan di luar kewajiban pribadinya. Hal ini terjadi karena dalam kepemimpinan transformasional, pemimpin selalu mendorong bawahannya untuk bertindak melebihi kepentingan pribadinya (Jahangir, et.al,2004). Bawahan didorong untuk bekerja secara tim, dan saling menghargai, dan menolong karyawan yang lainnya baik yang berhubungan dengan tanggung jawabnya maupun pekerjaan yang bukan menjadi tanggung jawabnya.

Selain kepemimpinan transformasional, kepuasan kerja yang dirasakan oleh karyawan juga dianggap menjadi salah satu faktor yang bisa menumbuhkan perilaku Organization 
citizenship behavior (MacKenzie et al. 1998). Seorang karyawan yang merasa puas dengan kerja dan lingkungan kerjanya akan cenderung loyal dengan organisasi dan akan memberikan kontribusi yang lebih pada kemajuan organisasi. Salah satu kontribusi yang dia berikan biasanya dia akan melakukan pekerjaan diluar tanggung jawabnya secara sukarela.

Di lingkungan sekolah, perilaku Organization citizenship behavior (OCB) sangat dibutuhkan untuk menunjang kesuksesan proses belajar mengajar, juga untuk mendukung organisasi dalam menghadapi persaingan yang semakin ketat. Seperti kita ketahui, di sekolah, ada dua pihak yang terkait dalam pelaksanaan operasional belajar mengajar. Pertama adalah tenaga pendidik, yang bertugas untuk melakukan proses belajar mengajar di kelas secara langsung, dan kedua adalah tenaga non pendidik, yang bertugas menyiapkan segala perangkat untuk kegiatan belajar mengajar, dari mulai administrasi, sarana, maupun sistem pengajaran. Meskipun dua pihak ini memiliki wilayah tanggung jawab yang berbeda, tetapi sebenarnya keduanya memiliki ketergantungan yang sangat tinggi. Guru sebagai tenaga pendidik tidak akan bisa melaksanakan tugasnya apabila perangkat pendidikan tidak disiapkan dengan baik. Begitu juga tenaga non pendidikan akan kesulitan menjalankan aktifitas tehnis, jika gurunya tidak melakukan proses belajar mengajar secara optimal. Disisi lain, tugas guru yang saat ini dituntut menjadi guru yang profesional, membawa imbas pada menumpuknya pekerjaan guru. Sehingga konsekwensinya, mereka harus menjalin kerja sama, saling bantu membantu untuk kesuksesan pekerjaan mereka. Mereka dituntut untuk mengembangkan perilaku Organization citizenship behavior (OCB) yang membawa mereka tidak hanya bekerja di wilayah tanggung jawab masing-masing, tetapi juga mengembangkan sikap untuk saling memahami, menghargai, dan bekerja melebihi tanggung jawabnya secara sukarela.

Berdasarkan latar belakang di atas, peneliti tertarik untuk mengambil judul penelitian · PENGARUH KEPEMIMPINAN TRANSFORMASIONAL DAN KEPUASAN KERJA TERHADAP ORGANIZATION CITIZENSHIP BEHAVIOR'

\section{LANDASAN TEORI}

\subsection{Kepemimpinan transformasional}

Banyak ahli menjelaskan tentang pengertian kepemimpinan transformasional. Munawaroh (2011) mengemukakan bahwa kepemimpinan transformasional digambarkan sebagai gaya kepemimpinan yang dapat membangkitkan atau memotivasi karyawan, sehingga dapat berkembang dan mencapai kinerja pada tingkat yang tinggi, melebihi dari apa yang mereka perkirakan sebelumnya. Wijaya (2005) berpendapat bahwa gaya kepemimpinan transformasional adalah pemimpinan yang mampu mendatangkan perubahan di dalam diri setiap individu yang terlibat dan/atau bagi seluruh organisasi untuk mencapai kinerja yang semakin tinggi. Secara lebih dalam Antonakis et al. (2003) menjelaskan bahwa kepemimpinan transformasional adalah 
perilaku yang bersifat proaktif, meningkatkan perhatian atas kepentingan bersama kepada para pengikut, dan membantu para pengikut mencapai tujuan pada tingkatan yang paling tinggi. Seorang pemimpin dengan gaya transformasional selalu berusaha membangkitkan semangat karyawannya untuk berkembang dan mencapai kinerja yang melampaui kinerja sebelumnya.

Adapun dimensi-dimensi kepemimpinan transformasional menurut (Bas\&Avolio (1998) adalah Pertama, Idealized Influence (Kharisma), adalah pemimpin yang mampu memberikan visi dan misi, menanamkan kebanggaan, inspirasi dan kepercayaan kepada pengikut serta tindakannya lebih mendahulukan kepentingan organisasi dan kepentingan orang lain dari kepentingan diri sendiri. Kedua, Inspirational Motivation (Inspirasi), adalah kemampuan pemimpin untuk memperluas wawasan bawahan dengan mengkaji ulang permasalahan lama dengan cara baru. Ketiga, Intellectual Stimulation (Stimulasi Intelektual), terkait dengan ingkat perhatian dan dukungan yang diberikan pemimpin pada bawahan. Keempat, Individuallized Consideration (Konsederasi yang Bersifat Individual), adalah kemampuan untuk memperlakukan secara berbeda-beda namun adil dan menyediakan sarana prasarana dalam rangka pencapaian tujuan serta memberikan pekerjaan menantang bagi bawahan yang menyukai tantangan.

\subsection{Organizational Citizenship Behavior}

Organization citizenship behavior (OCB) adalah suatu sikap perilaku karyawan yang dilakukan dengan sukarela, tulus, senang hati tanpa harus diperintah dan dikendalikan oleh perusahaan dalam memberikan pelayanan dengan baik (Organ et al., 2006). Menurut Robbin (2008), organization citizenship behavior adalah perilaku perilaku kerja yang ditunjukkan oleh karyawan yang melebihi tanggung jawabnya, akan tetapi berdampak baik karena mendukung efektifitas kerja organisasi. Secara umum dapat disimpulkan bahwa seorang karyawan dengan tingkat organization citizenship behavior tinggi akan bersedia bekerja melebihi tanggung jawabnya dalam rangka untuk mendukung efektifitas organisasi.

Dimensi OCB menurut Organ et al. (2006) adalah sebagai berikut :

a. Altruism, adalah perilaku karyawan dalam menolong rekan kerjanya yang mengalami kesulitan dalam situasi yang sedang dihadapi baik mengenai tugas dalam organisasi maupun masalah pribadi orang lain.

b. Conscientiousness, adalah perilaku yang ditunjukkan dengan berusaha melebihi yang diharapkan perusahaan. Perilaku sukarela yang bukan merupakan kewajiban atau tugas karyawan. Dimensi ini menjangkau jauh diatas dan jauh ke depan dari panggilan tugas

c. Sportmanship, adalah perilaku yang memberikan toleransi terhadap keadaan yang kurang ideal dalam organisasi tanpa mengajukan keberatan - keberatan. 
d. Courtessy, adalah menjaga hubungan baik dengan rekan kerjanya agar terhindar dari masalah - masalah interpersonal.

e. Civic Virtue, adalah perilaku yang mengindikasikan tanggung jawab pada kehidupan organisasi (mengikuti perubahan dalam organisasi, mengambil inisiatif untuk merekomendasikan bagaimana operasi atau prosedur - prosedur organisasi dapat diperbaiki, dan melindungi sumber - sumber yang dimiliki oleh organisasi).

\subsection{Kepuasan Kerja}

Banyak ahli yang menjelaskan tenatng pengertian kepuasan kerja. Handoko (2009) menyatakan bahwa kepuasan kerja adalah keadaan yang menyenangkan atau tidak menyenangkan, dengan mana seorang pegawai memandang pekerjaan mereka. Malthis, 2008 dalam Rosita et all (2016) menyatakan bahwa kepuasan kerja adalah keadaan emosi yang positif dari mengevaluasi pengalaman kerja seseorang. Kepuasan kerja sikap para pekerja mengenai pekerjaannya yang dihasilkan dari persepsi mereka terhadap pekerjaannya berdasarkan faktorfaktor yang terdapat dalam lingkungan kerja seperti gaya penyelia, kebijakan dan prosedur, afiliasi kelompok kerja, kondisi kerja, dan manfaat lainnya bagi pekerja ( Gibson et al., 2009). Ini berarti bahwa kepuasaan kerja dapat dimaknai sebagai perasaan seseorang akan pekerjaan yang dihadapi.

Menurut Luthans (2006), dimensi kepuasan kerja yaitu gaji, pekerjaan itu sendiri, supervisi, promosi, dan rekan kerja

\subsection{Penelitian Sebelumnya}

Sudah banyak peneliti yang mencoba meneliti faktor-faktor yang menentukan perilaku Organization citizenship behavior (OCB). Shweta and Srirang (2010) dalam penelitian kajian literatur mereka menyebutkan bahwa kepemimpinan transformasional dan kepuasan kerja menjadi salah satu faktor yang mempengaruhi perilaku Organization citizenship behavior (OCB). Sementara hubungan antara kepemimpinan transformasional dengan Organization citizenship behavior (OCB) ditengarai memiliki pengaruh yang positif. Artinya semakin organisasi menerapkan kepemimpinan transformasional, maka Organization citizenship behavior (OCB) karyawan akan semakin meningkat. Pemimipin yang menerapkan gaya kepemimpinan transformasional akan cenderung memotivasi bawahannya untuk bekerja dengan inisiatif tinggi, berorientasi mencapai tujuan organisasi, memberikan wewenang dalam beberapa pekerjaan, dan selalu mendorong bawahannya untuk bekerja melebihi tanggung jawab pribadinya. 
Lian dan Tui (2012) melakukan penelitian pada 347 responden yang mewakili industri seperti perusahaan jasa, manufaktur, pertambangan dan konstruksi. Hasil penelitiannya menunjukkan bahwa gaya kepemimpinan transformasional memiliki hubungan positif yang signifikan terhadap Organization citizenship behavior (OCB) bawahan. Menurut Jahangir et al. (2004), gaya kepemimpinan memiliki pengaruh yang kuat pada kesediaan karyawan untuk terlibat dalam Organization citizenship behavior (OCB). Penelitian yang dilakukan oleh Nguni (2005) pada sekolah-sekolah dasar dan sekolah menengah di Tanzania juga menunjukkan pengaruh yang signifikan dan positif antara kepemimpinan transformasional terhadap perilaku Organization citizenship behavior (OCB) dari para guru. Dhipura dan Rahyuda (2015) dalam penelitiannya membuktikan bahwa Kepemimpinan transformasional berpengaruh secara langsung pada variabel organizational citizenship behavior.

Berdasarkan beberapa hasil penelitian yang diungkapkan diatas, maka dapat dirumuskan hipotesis penelitian sebagai berikut:

H1 : Kepemimpinan transformasional berpengaruh positif terhadap Organization citizenship behavior (OCB).

Menurut Robbins dan Judge (2008), kepuasan kerja seharusnya menjadi faktor penentu utama dari Organizational Citizenship Behavior( OCB) seorang karyawan. Karyawan yang puas cenderung berbicara secara positif tentang organisasi, membantu individu lain, dan melewati harapan normal dalam pekerjaan mereka. Selain itu, karyawan yang puas lebih mudah berbuat lebih dalam pekerjaan karena mereka ingin merespons pengalaman positif mereka. Hasil study yang dilakukan oleh MacKenzie et al. (1998) juga menunjukkan bahwa kepuasan kerja memotivasi karyawan untuk melakukan Organization citizenship behavior (OCB) secara sukarela. Murphy et al. (2002) menemukan bahwa kepuasan kerja memiliki hubungan yang signifikan dan positif terhadap Organization citizenship behavior (OCB). Dhipura dan Rahyuda (2015)) dalam penelitiannya membuktikan bahwa Kepuasan kerja berpengaruh secara langsung pada variabel organizational citizenship behavior.

\section{H2 : Kepuasan kerja berpengaruh positif dan signifikan terhadap} Organization citizenship behavior (OCB)

Sementara itu, beberapa penelitian juga berhasil menjelaskan hubungan antara kepemimpinan transformasional dan kepuasan kerja. Griffith (2004) membuktikan bahwa 
sekolah di mana kepala sekolahnya nenerapkan gaya kepemimpinan transformasional memiliki staf sekolah yang lebih puas dengan pekerjaan mereka. Zahari dan Shurbagi (2012) melakukan penelitian terhadap karyawan dari National Oil Corporation Libya. Hasil penelitiannya menunjukkan hubungan positif yang signifikan antara gaya kepemimpinan transformasional dengan kepuasan kerja karyawan.

H3 : Kepemimpinan transformasional berpengaruh positif dan signifikan terhadap kepuasan kerja.

Selain pengaruh langsung antara kepemimpinan transformasional dan organizational citizenship behavior, adanya variabel kepuasan kerja diprediksi menimbulkan pengaruh tidak langsung antara kepemimpinan transformasional dengan organizational citizenship behavior. Organ (1988) dalam Podsakoff et al (1990) mengatakan bahwa variabel pengikut dari kepemimpinan transformasional diindikasikan menjadi variabel mediating dalam hubungan antara variabel kepemimpinan transformasional dan organizational citizenship behavior. Dan salah satu variabel pengikut tersebut adalah kepuasan kerja. Penelitian yang dilakukan oleh Kartono et al ( 2015) membuktikan bahwa Kepuasan kerja menjadi variabel mediating/intervening pada hubungan antara variabel kepemimpinan transformasional dan OCB. Penelitian lainnya yang dilakukan oleh Podsakoff et al (1990) juga membuktikan bahwa kepuasan kerja menjadi mediating variabel untuk hubungan antara kepemimpinan transformasinal dan organizational citizenship behavior. Penelitian Nguni et al (2007) membuktikan bahwa kepemimpinan transformasional berpengaruh positif dan langsung terhadap kepuasan kerja dan organizational citizenship behavior, sementara kepuasan kerja sendiri juga menjadi variabel mediating hubungan kedua variabel tersebut. Ngadiman et al (2013) menemukan bahwa kepemimpinan transformasional berpengaruh langsung terhadap kepuasan kerja, dan kepuasan kerja berpengaruh secara langsung terhadap organizational citizenship behavior. Kepemimpinan transformasional tidak berpengaruh langsung terhadap organizational citizenship behavior, tetapi secara tidak langsung berpengaruh terhadap organization citizenship behavior dengan dimediasi oleh variabel kepuasan kerja

H4 : Kepemimpinan transformasional berpengaruh positif terhadap organization citizenship behavior (OCB) melalui intervening variable kepuasan kerja 
Dalam penelitian ini, hubungan masing-masing variabel dibangun menggunakan persamaan jalur $\mathrm{Y}=\rho_{\mathrm{yx} 1} \mathrm{X} 1+\rho_{\mathrm{yx} 2} \mathrm{X} 2+\rho_{\mathrm{y \varepsilon}}$

\section{KONSTALASI HUBUNGAN ANTAR VARIABEL}

Konstelasi hubungan antar variabel dalam penelitian ini dapat digambarkan sebagai berikut :

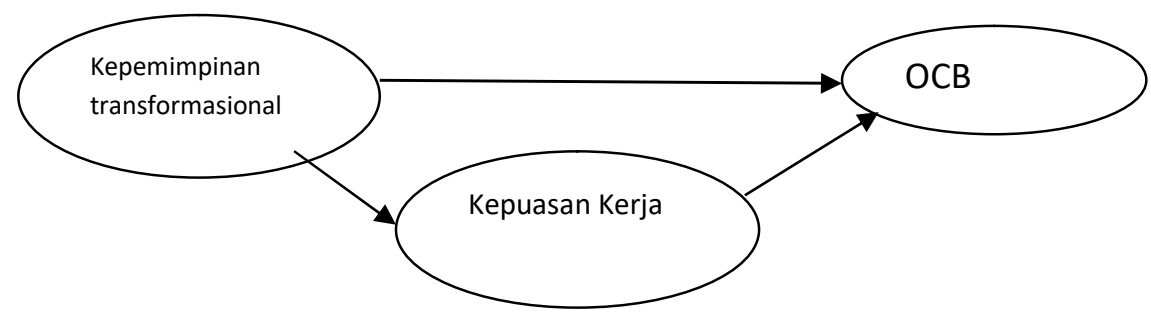

\section{METODE PENELITIAN}

Penelitian ini merupakan penelitian korelasional yang bertujuan untuk menganalisis pengaruh variabel kepemimpinan transformasional dan kepuasan kerja terhadap organization citizenship behavior (OCB).

\subsection{Populasi dan Sample}

Populasi dalam penelitian ini adalah seluruh karyawan islamic boarding school setingkat SMA yang ada di Yogyakarta. Populasi terjangkau dibatasi hanya pada Islamic boarding school setingkat SMA terpilih yang sudah menerapkan kepemimpinan transformasional. Tehnik pengambilan sampel menggunakan tehnik purposive random sampling, dimana sampel diambil dari s ekolah yang sudah menerapkan kepemimpinan transformasional, dan karakterisitik guru/karyawan adalah berstatus guru/karyawan tetap. Karena keterbatasan waktu dan biaya yang dimiliki peneliti, maka dalam penelitian ini hanya diambil 3 sekolah yang mudah diakses, mewakili 3 wilayah di Yogyakarta, yaitu MA Nurul Ummah Kotagede Bantul, MA Nuriman Mlangi Sleman, dan MA Mualimin Yogyakarta. Jumlah sampel total 86, dengan perincian masing-masing sekolah dapat dilihat pada tabel berikut ini :

Tabel 3. Sampel Penelitian

\begin{tabular}{|l|l|l|l|l|}
\hline \multirow{2}{*}{ NO } & \multirow{2}{*}{ SEKOLAH } & \multicolumn{2}{c|}{ JUMLAH SAMPEL } & \multirow{2}{*}{ TOTAL } \\
\cline { 3 - 4 } & & GURU & KARYAWAN & \\
\hline 1 & MA NURUL UMMAH & 12 & 11 & 23 \\
\hline 2 & MA NUR IMAN & 12 & 8 & 20 \\
\hline 3 & MA MUALIMIN & 24 & 19 & 43 \\
\hline & TOTAL & 48 & 38 & 86 \\
\hline
\end{tabular}




\subsection{Definisi Konseptual dan Operasional}

Instrumen penelitian dirancang berdasarkan dimensi yang ada dalam teori dan penelitian sebelumnya. Kuesioner dibuat berdasarkan rumusan kuesiner yang dikembangkan oleh peneliti sendiri. Definisi konseptual dan operasional masing-masing variabel dapat dirumuskan sebagai berikut :

1. Kepemimpinan transformasional (variabel independen), adalah perilaku yang bersifat proaktif, meningkatkan perhatian atas kepentingan bersama kepada para pengikut, dan membantu para pengikut mencapai tujuan pada tingkatan yang paling tinggi (Antonakis et al. 2003). Kepemimpinan transformasional diukur dengan menggunakan kuesioner skala likert 1-5 yang mencerminkan dimensi Idealized Influence (Kharisma), Behavioral influence ( integrity), Inspirational Motivation (Inspirasi), Intellectual Stimulation (Stimulasi Intelektual), Individuallized Consideration (Konsederasi yang Bersifat Individual).

2. Kepuasan kerja (variabel independen), adalah sikap para pekerja mengenai pekerjaannya yang dihasilkan dari persepsi mereka terhadap pekerjaannya berdasarkan faktor-faktor yang terdapat dalam lingkungan kerja seperti gaya penyelia, kebijakan dan prosedur, afiliasi kelompok kerja, kondisi kerja, dan manfaat lainnya bagi pekerja ( Gibson et al., 2009). Dalam penelitian ini kepuasan kerja diukur dengan menggunakan kuesioner skala likert 1-5 yang mencerminkan dimensi kepuasan kerja itu sendiri, yaitu gaji, pekerjaan itu sendiri, supervisi, promosi, dan rekan kerja

3. Organization citizenship behavior $(O C B)$ variabel dependen, adalah perilaku individual yang bersifat bebas (discretionary), yang tidak secara langsung dan eksplisit mendapat penghargaan dari sistem imbalan formal, dan yang secara keseluruhan (agregat) meningkatkan efisiensi dan efektifitas fungsi-fungsi organisasi, bersifat bebas dan sukarela, karena perilaku tersebut tidak diharuskan oleh persyaratan peran atau deskripsi jabatan yang secara jelas dituntut berdasarkan kontrak dengan organisasi, melainkan sebagai pilihan personal (Organ et al., 2006). Dalam penelitian ini Organization citizenship behavior (OCB) diukur dengan menggunakan kuesioner skala likert 1-5 yang mencerminkan dimensi altruism, courtacy, sportmanship, conciouness, civic virtue.

\subsection{Analisis data}


Instrumen penelitian terlebih dahulu akan dianalisis validitas dan reliabilitasnya. Uji validitas menggunakan korelasi Pearson dan uji reliabilitas dengan menggunakan Alpha Cronbanch yang diolah dengan menggunakan SPSS 17, hal ini untuk memastikan bahwa kuesioner yang akan kita sebar valid dan reliabel untuk digunakan pada sampel penelitian yang bersangkutan. Hipotesis penelitian akan diuji dengan menggunakan analisis jalur (path analysis). Sebelum melakukan analisis jalur, terlebih dahulu dilakukan uji persayaratan analisis yang terdiri dari uji normalitas, linieritas, heteroskedasitas, dan uji multikolonieritas.

\subsection{Desain Diagram}

Model persamaan jalur dalam penelitian ini dapat dinyatakan sebagai berikut:

$$
\begin{aligned}
& \mathrm{X} 2=\rho_{\mathrm{x} 2 \mathrm{x} 1} \mathrm{X} 1+\rho_{\mathrm{x} 2 \varepsilon} \\
& \mathrm{Y}=\rho_{\mathrm{yx} 1} \mathrm{X} 1+\rho_{\mathrm{yx} 1} \mathrm{X} 2+\rho_{\mathrm{y} \varepsilon}
\end{aligned}
$$

Dimana Y mewakili variabel Organization Citizenship Behavior (OCB), X1 mewakili variabel kepemimpinan Transformasional (KT), dan X2 mewakili variabel Kepuasan Kerrja (KK)

Desain penelitian dapat digambarkan seperti diagram dibawah ini :

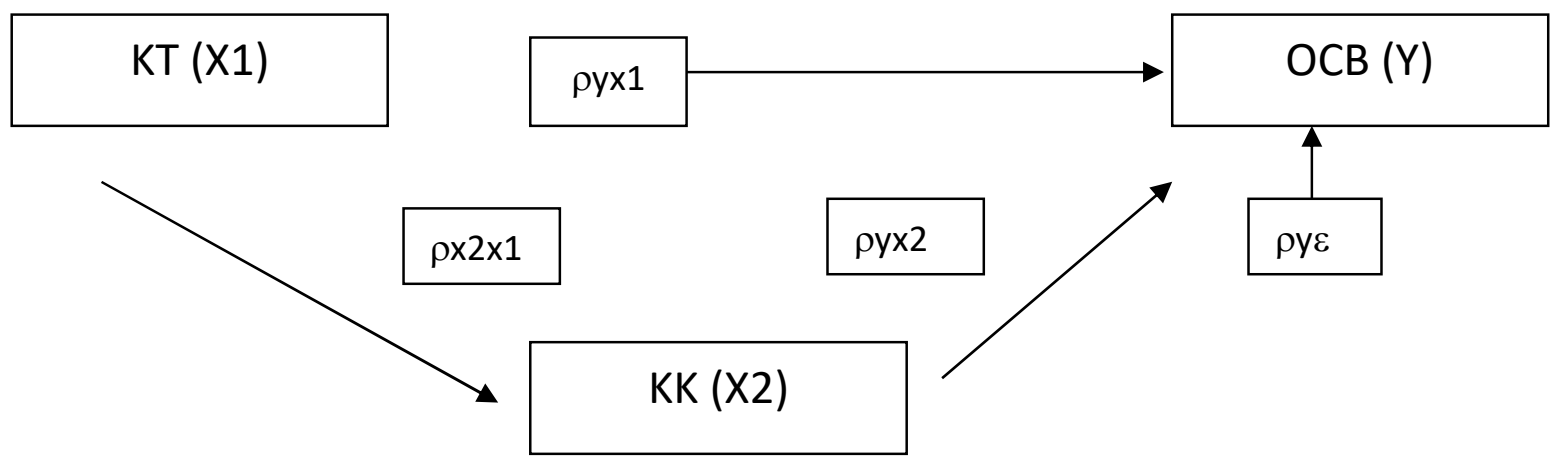

\section{HASIL DAN PEMBAHASAN}

\subsection{Uji Validitas dan Uji Reliabilitas}

Seluruh instrumen yang akan digunakan untuk penelitian, sebelumnya dilakukan uji coba terlebih dahulu kepada 30 karyawan di sekolah yang bersangkutan. Dari uji coba tersebut dilakukan perhitungan uji validitas instrumen dengan menghitung koefisien korelasi setiap item terhadap nilai totalnya dengan menggunakan Pearson Correlation. 
Kriteria yang digunakan adalah nilai $r$ yang dibandingkan dengan nilai r-tabel. Instrumen dianggap valid jika nilai $r>$ nilai $r$-tabel sebesar 0,361 . Selain uji validitas, juga dilakukan uji reliabilitas dengan menggunakan nilai cronbach alpha.

\subsection{Uji Persyaratan Analisis Data}

Sebelum dilakukan uji analisis data, maka terlebih dahulu harus dilakukan uji persyaratan analisis data, yang terdiri dari uji normalitas, uji reliabilitas, dan uji heteroskedasitas. Uji persyaratan analisis dilakukan untuk memastikan bahwa data yang digunakan sudah bebas dari masalah dan siap digunakan untuk analisis data selanjutnya.

Uji normalitas data dilakukan dengan menggunakan uji Kolmogorov-Smirnov untuk diperoleh nilai signifikansi masing masing variabel baik variabel dependen maupun variabel independen. Kriteria pengujian hipotesis diketahui bahwa Ho diterima apabila nilai signifikansi lebih besar dari taraf signifikansi 0,05, yang artinya data berdistribusi normal. Dari hasil perhitungan dapat dilihat bahwa perolehan nilai signifikansi ( $p$-value) sebesar 0,698. Hasil tersebut menunjukkan nilai yang lebih besar bila dibandingkan dengan taraf signifikansinya $(0,698>0,05)$ sehingga data variabel memenuhi persyaratan data berdistribusi normal.

Untuk mengetahui apakah regresi antar variabel yang diteliti linear atau tidak maka dilakukan uji linearitas. Kriteria pengujian linieritas dengan menggunakan SPSS dapat dilakukan dengan melihat nilai deviation from linearity harus lebih besar dari taraf signifikansi 5\%. Perhitungan data menyajikan hasil uji linearitas antara variabel independent $(\mathrm{X})$ terhadap variabel dependen $(\mathrm{Y})$ dimana besarnya nilai signifikansi pada deviation from linearity lebih besar dari taraf signifikansi 5\%. Hal ini menunjukkan penerimaan terhadap Ho dan dapat diartikan bahwa hubungan antar variabel linier linear.

Uji heteroscedastisitas adalah uji terakhir yang dilakukan dalam uji persyaratan analisis data. Uji heteroskedasitas dilakukan dengan menggunakan perhitungan korelasi Rank Spearman. Korelasi Rank Spearman digunakan untuk melihat hubungan antara variabel independen dengan residualnya.

Dengan melihat ouput data penelitian, nilai signifikansi ( $p$-value) untuk hubungan antara masing-masing variabel dengan residualnya semua berada pada nilai lebih besar dibandingkan taraf signifikansi 5\%. Hal ini menunjukkan bahwa Ho diterima, yang artinya tidak terjadi heteroskedastisitas pada variabel yang diteliti. 


\subsection{Perhitungan Koefisien Jalur}

Untuk mencari koefisien jalur, maka dapat dilakukan dengan menggunakan SPSS dengan mencari nilai standardized coefficients. Seperti dalam gambar konstalasi hubungan di bab 3, maka proses menghitung koefisien jalur akan dilakukan dua kali. Pertama mencari koefisien jalur utuk hubungan variabel kepemimpinan transformasional dan variabel kepuasan kerja, dan kedua baru mencari koefisien jalur untuk hubungan antara kepemimpinan transformasional dan kepuasan kerja terhadap OCB. Berdasar tabel 4.1 diketahui bahwa koefisien jalur antara variabel kepemimpinan transformasional dan variabel kepuasan kerja adalah 0,681; Sedang berdasar tabel 4.2 diketahui bahwa koefisien jalur antara variabel kepemimpinan transformasional dan OCB adalah 0,309; Dan untuk koefisien jalur antara variabel kepuasan kerja dan OCB adalah sebesar 0,346.

Dari hasil perhitungan koefisien jalur dapat disusun persamaan jalur sebagai berikut :

$$
\begin{aligned}
& \mathrm{X} 2=0,681 \mathrm{X} 1+\rho_{\mathrm{x} 2 \varepsilon} \\
& \mathrm{Y}=\mathbf{0 , 3 0 9} \mathrm{X} 1+0,346 \mathrm{X} 2+\rho_{\mathrm{y} \varepsilon}
\end{aligned}
$$

\begin{tabular}{|c|c|c|c|c|c|c|}
\hline \multicolumn{7}{|c|}{ Coefficients $^{a}$} \\
\hline \multirow{2}{*}{\multicolumn{2}{|c|}{ Model }} & \multicolumn{2}{|c|}{ Unstandardized Coefficients } & \multirow{2}{*}{$\begin{array}{c}\text { Standardized } \\
\text { Coefficients } \\
\text { Beta }\end{array}$} & \multirow[b]{2}{*}{$\mathrm{t}$} & \multirow[b]{2}{*}{ Sig. } \\
\hline & & B & Std. Error & & & \\
\hline \multirow[t]{2}{*}{1} & (Constant) & 29,053 & 5,435 & & 5,346 &, 000 \\
\hline & $\mathrm{kt}$ & ,359 & ,042 & ,681 & 8,515 & ,000 \\
\hline
\end{tabular}

Tabel 4.1 Koefisien Jalur Antara Kepemimpinan Transformasional dan Kepuasan Kerja

a. Dependent Variable: kk

\begin{tabular}{|c|c|c|c|c|c|c|}
\hline \multicolumn{7}{|c|}{ Coefficients $^{\mathrm{a}}$} \\
\hline \multirow{2}{*}{\multicolumn{2}{|c|}{ Model }} & \multicolumn{2}{|c|}{ Unstandardized Coefficients } & \multirow{2}{*}{$\begin{array}{c}\text { Standardized } \\
\text { Coefficients } \\
\text { Beta } \\
\end{array}$} & \multirow[b]{2}{*}{$t$} & \multirow[b]{2}{*}{ Sig. } \\
\hline & & B & Std. Error & & & \\
\hline \multirow[t]{3}{*}{1} & (Constant) & 12,034 & 5,559 & & 2,165 & 033 \\
\hline & kk & ,279 & ,096 & ,346 & 2,890 & ,005 \\
\hline & $\mathrm{kt}$ & 131 & ,051 & ,309 & 2,582 & ,012 \\
\hline
\end{tabular}

Tabel 4.2 Koefisien Jalur Antara Variabel Dependent da Variabel Independent 
a. Dependent Variable: ocb

\subsection{Analisis Koefisien Jalur}

Untuk melakukan pengujian terhadap model yang sudah dibuat, bisa dilihat pada perhitungan nilai $\mathrm{F}$ menggunakan SPSS 17. Untuk model hubungan antara variabel kepemimpinan transformasional dan kepuasan kerja, berdasar tabel 4.3 dapat diketahui nilai $\mathrm{F}$ hitung adalah 72,508 dengan nilai signifikansinya 0,000. Hasil ini menunjukkan bahwa model pertama signifikan dan berarti. Untuk pengujian model secara simultan antara variabel independen kepemimpinan transformasional dan kepuasan kerja terhadap variabel dependen OCB, dapat dilihat pada tabel 4.4 yang menunjukkan perolehan nilai F hitung sebesar 23,455 dengan nilai signifikansi 0,000. Hasil ini juga menunjukkan bahwa model kedua yang diajukan signifikan dan berarti.

Tabel 4.3

\begin{tabular}{|c|c|c|c|c|c|c|}
\hline \multicolumn{7}{|c|}{ ANOVA $^{b}$} \\
\hline & & Sum of Squares & $\mathrm{df}$ & Mean Square & $\mathrm{F}$ & Sig. \\
\hline \multirow[t]{3}{*}{1} & Regression & 1804,067 & 1 & 1804,067 & 72,508 &, $000^{a}$ \\
\hline & Residual & 2089,991 & 84 & 24,881 & & \\
\hline & Total & 3894,058 & 85 & & & \\
\hline
\end{tabular}

a. Predictors: (Constant), kt

b. Dependent Variable: kk

Tabel 4.4

ANOVA $^{b}$

\begin{tabular}{|c|c|c|c|c|c|c|}
\hline \multicolumn{2}{|c|}{ Model } & Sum of Squares & df & Mean Square & $\mathrm{F}$ & Sig. \\
\hline \multirow[t]{3}{*}{1} & Regression & 911,281 & 2 & 455,641 & 23,455 &, $000^{a}$ \\
\hline & Residual & 1612,358 & 83 & 19,426 & & \\
\hline & Total & 2523,640 & 85 & & & \\
\hline
\end{tabular}

a. Predictors: (Constant), kt, kk

b. Dependent Variable: ocb

Secara parsial, hubungan masing-masing variabel independent dapat dilihat pada hasil perhitungan di tabel 4.1 dan 4.2. Hubungan antara variabel kepemimpinan transformasional dan kepuasan kerja dapat berdasarkan tabel 4.1 berada pada nilai thitung 0,515 dengan taraf signifikansi 0,000. Ini berarti bahwa kedua variabel memiliki 
pengaruh langsung positif dan signifikan. Selanjutnya hubungan antara variabel kepemimpinan transformasional terhadap variabel organization citizenship behavior, dan variabel kepuasan kerja terhadap organization citizenship behavior berdasar tabel 4.2 menunjukkan nilai t-hitung masing-masing 2,289 dan 2, 582 dengan taraf signifikansi 0,005 dan 0,012. Ini menunjukkan bahwa kedua variabel independent memiliki pengaruh langsung dan signifikan terhadap variabel dependent. Lebih jelas pengaruh langsung dan tidak langsung masing-masing variabel independen terhadap variabel dependen dapat digambarkan pada bagan berikut :

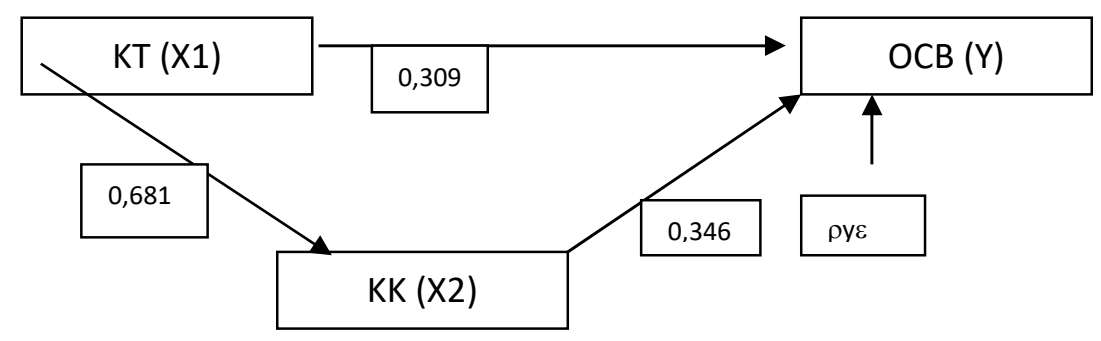

Tabel 4.5 menunjukkan hasil perhitungan koefisien determinasi. Berdasar tabel tersebut diketahui bahwa nilai determinasinya adalah 0,361 atau $36,1 \%$. Ini berarti bahwa kedua variabel independent mempengaruhi variabel dependent sebesar $36,1 \%$, sementara sebanyak 63,9\% dipengaruhi oleh variabel lain yang tidak diteliti. 
Tabel 4.5 Koefisien Determinasi

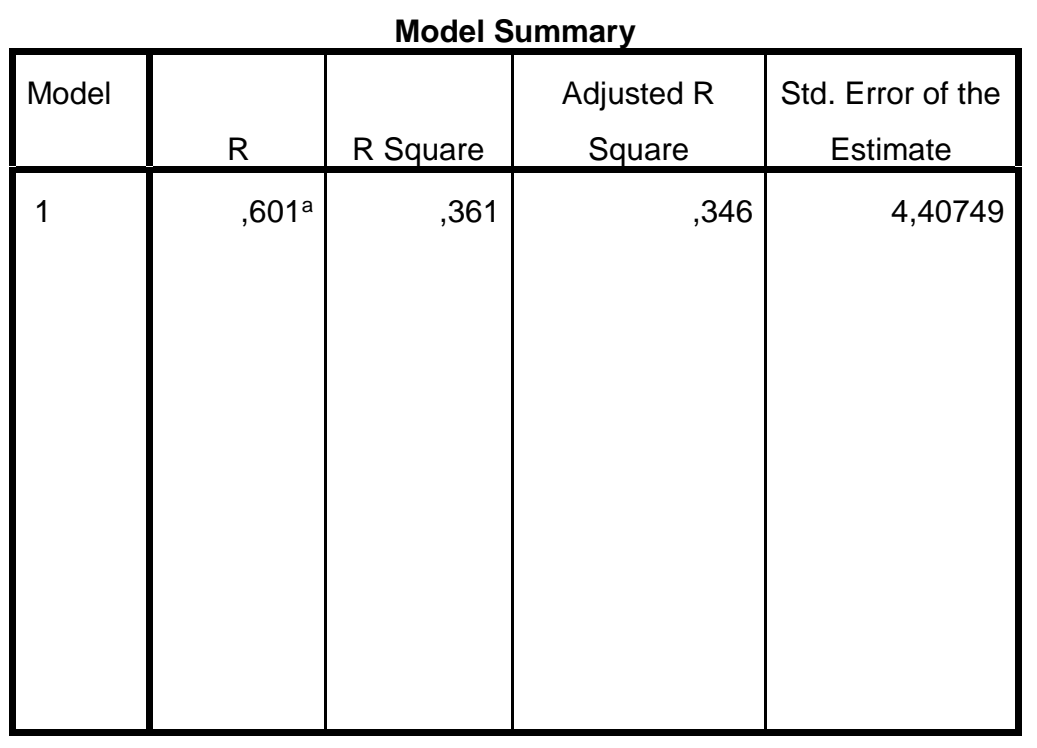

a. Predictors: (Constant), kt, kk

\subsection{Pembahasan}

Berdasar hasil penelitian diketahui bahwa kedua mdel hubungan yang ditawarkan menunjukkan model yang signifikan dengan nilai signifikanis 0,000. Pada model yang pertama $\mathbf{X} 2=\mathbf{0 , 6 8 1} X \mathbf{1}+\boldsymbol{\rho}_{\mathbf{x} 2 \varepsilon}$ variabel kepemimpinan mempengaruhi secara langsung dan positif variabel kepuasan kerja dengan koefisien pengaruh 0,681. Ini berarti bahwa apabila variabel kepemimpinan naik 1 digit, maka variabel kepuasan kerja juga akan meningkat sebesar 0,681 digit, dan sebaliknya. Lembaga/institusi pendidikan, apabila sudah menetapkan kebijakan menggunakan kepemimpinan transformasional, maka tingkat penerapan kepemimpinan transformasional yang dilakukan oleh kepala sekolah akan mempengaruhi kepuasan kerja. Semakin transformatif seorang pemimpin maka semakin kepuasan kerja guru dan karyawan akan meningkat. Begitu juga sebaliknya jika kurang dalam penerapannya, akan menurunkan tingkat kepuasan kerja guru/karyawan yang bersangkutan. Hal ini wajar, karena dalam kepemimpinan transformasional, pemimpin akan memberikan kepercayaan dan kebebasan secara penuh kepada karyawan untuk berekspresi dan bekerja sesuai target yang sudah diberikan. Disamping itu pimpinan akan mengedepankan kesetaraan dalam memimpin, dan berkomunikasi. Proses memanusiakan guru dan karyawan ini yang akan meningkatkan kepuasan karyawan yang dipimpin.

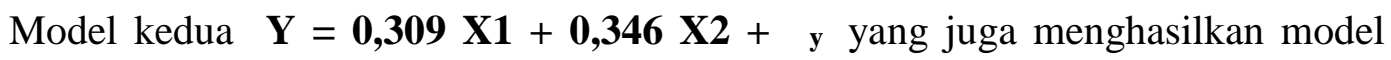
signifikan, mengindikasikan bahwa masing-masing variabel independent, baik variabel JURNAL APLIKASI BISNIS, Vol.17 No.2 Bulan Desember Tahun 2017. 
kepemimpinan transformasional maupun variabel kepuasan kerja memiliki pengaruh yang langsung dan positif terhadap variabel organization citizenship behavior. Semakin penerapan kepemimpinan transformasional naik, maka semakin budaya organizational citizenship behavior akan naik, dan sebaliknya. Pemimpin transformasional selalu mendorong karyawannya untuk bekerja dalam tim, saling mendukung dan membantu satu sama lain meskipun tidak dalam wewenang pekerjaannya. Budaya ini yang disebut sebagai organization citizenship behavior. Dalam dunia pendidikan proses OCB ini sering terjadi dalam pekerjaan antar guru, antar karyawan, atau antar guru dan karyawan.

Disisi lain, model kedua juga menunjukkan hubungan langsung positif antara variabel kepuasan kerja terhadap organization citizenship behavior. Semakin guru dan karyawan kepuasan kerja nya meningkat, maka semakin OCB mereka juga meningkat. Karyawan yang merasa puas terhadap perusahaan/lembaga, maka mereka akan memberikan komitmen yang lebih kepada perusahaan. Salah satu bentuk komitmen tersebut adalah keinginan secara sukarela untuk membantu teman-temannya dengan tujuan agar tujuan perusahaan bisa tercapai. Hubungan yang menarik ditunjukkan Dari model satu dan dua, dimana disimpulkan adanya peran moderating variabel kepuasan kerja dalam memperkuat hubungan antara variabel kepemimpinan transformasional terhadap organization citizenship behavior. Ini berarti bahwa, selain pengaruh langsung, kepemimpinan transformasional juga memiliki pengaruh tidak langsung terhadap OCB apabila bersama-sama dengan variabel kepuasan kerja. Artinya, pengaruhnya menjadi semakin kuat ketika dimasukkan variabel kepuasan kerja. Penerapan kepemimpinan transformasional di sekolah, akan memberikan pengaruh yang lebih kuat jika dibarengi dengan sistem kerja yang memberikan kepuasan kerja pada guru dan karyawan. Semakin pemimpin transformatif, dan semakin kepuasan kerja tercapai, maka organization citizenship behavior akan semakin meningkat. Selain itu dari nilai koefisien determinasi diperoleh $36,1 \%$. Ini berarti bahwa variabel kepemimpinan transformasional dan variabel kepuasan kerja baru memberikan pengaruh terhadap organization citizenship behavior sebesar 36,1\%. Agar budaya organization citizenship behavior ini bisa ditingkatkan lagi, maka sekolah harus menyertakan variabel lain yang mungkin juga berpengaruh terhadap organization citizenship behavior.

\section{KESIMPULAN}

\subsection{Kesimpulan}


1. Penelitian ini mencoba menganalisis hubungan antara variabel kepemimpinan transformasional dan variabel kepuasan kerja terhadap variabel organization citizenship behavior pada sekolah islam berbasis boarding school di Yogyakarta. Sample yang digunakan adalah guru dan karyawan di 3 sekolah, yaitu MA nurul Ummah Kotagede Bantul, MA Nuriman Mlangi Sleman, dan MA Mualimin Yogyakarta.

2. Hasil perhitungan analisis jalur menunjukkan bahwa secara simultan variabel independen kepemimpinan transformasional dan kepuasan kerja memiliki pengaruh terhadap variabel dependen organization citizenship behavior, dengan ditunjukkan oleh nilai f-hitung sebesar 23,455 dengan taraf signifikansi sebesar 0,000. Persamaan model yang dihasilkan adalah $\mathrm{X} 2=0,681 \mathrm{X} 1+\rho_{\mathrm{x} 2 \varepsilon}$ dan $\mathrm{Y}=0,309 \mathrm{X} 1+0,346 \mathrm{X} 2+$ $\rho_{\mathrm{y \varepsilon}}$. Selain pengaruh simultan, dari dua model tersebut dapat disimpulkan adanya pengaruh moderating variabel kepuasan kerja dalam hubungan antara variabel kepemimpinan transformasional dan variabel organization citizenship behavior.

3. Secara parsial, variabel kepemimpinan transformasional dan kepuasan kerja juga memiliki pengaruh langsung terhadap organization citizenship behavior, yang ditunjukkan oleh nilai t-hitung 2,289 dan 2, 582 dengan taraf signifikansi 0,005 dan 0,012 .

4. Perhitungan koefisien determinasi menunjukkan bahwa variabel kepemimpinan transformasional dan kepuasan kerja mempengaruhi variabel organization citizenship behavior sebesar $36,1 \%$, sedang sisanya dipengaruhi oleh variabel lain yang tidak diteliti.

\subsection{Implikasi}

1. Secara teoritis, hasil penelitian ini akan memperkuat teori-teori sebelumnya, terkait dengan hubungan antara variabel kepemimpinan transformasional, kepuasan kerja, dan organisational citizenship behavior. Ke depan penelitian juga bisa dikembangkan untuk memetakan pelaksanaan OCB di lingkungan sekolah, serta menambahkan variabel kinerja sebagai dampak dari penerapan kepemimpinan transformasional dan budaya OCB.

2. Secara manajerial, hasil penelitian ini akan berguna sebagai dasar kebijakan SDM dalam membuat program untuk meningkatkan kepuasan karyawan dan meningkatkan peran karyawan dalam mendukung efektifitas organisasi, serta implementasi 
kepemimpinan yang mampu mendorong partisipasi karyawan secara lebih mendalam dalam memajukan organisasi.

\subsection{Keterbatasan Penelitian}

Keterbatasan dari penelitian ini adalah jumlah sampel yang terbatas pada sekolahsekolah yang bisa diakses oleh peneliti. Hal ini terjadi karena keterbatasan waktu yang dimiliki oleh peneliti, dan persepsi dan kesadaran dari sekolah yang masih menganggap bahwa partisipasi dalam sebuah penelitian hanya akan membuang-buang waktu.

\section{SARAN}

1. Sekolah perlu mengontrol penerapan kepemimpinan transformasional yang dilakukan oleh masing-masing kepala sekolahnya, agar penerapannya optimal sesuai dengan prinsip-prinsip kebiajakan yang sudah ditetapkan.

2. Sekolah harus selalu mengkampanyekan kesadarn budaya organization citizenship behavior, kepada seluruh guru dan karyawan, dalam rangka membangun tim kerja yang baik sehingga pencapaian kinerja sekolah bisa menjadi lebih baik dari sebelumnya.

3. Ke depan bisa dilakukan penelitian sejenis dengan memasukkan variabel lain yang mungkin juga mempengaruhi organization citizenship behavior dengan melibatkan sekolah dalam wilayah yang lebih luas di seluruh wilayah Yogyaakarta 


\section{DAFTAR PUSTAKA}

Antonakis, J., Avolio, B.J., and Sivasubramaniam, N. 2003. Context and Leadership: An Examination of the Nine Factor Full-Range Leadership Theory Using the Multifactor Leadership Questionnaire, The Leadership Quarterly, Vol 14, No 2, pp. 261-295.

Asiah, 2016, Efektifitas Kinerja Guru, TADBIR : Jurnal Manajemen Pendidikan Islam, Vol 4, No. 2

Bass, Bernard M \& Avolio, Bruce J. 1998. "Improving Organizational Effectiveness Through

Transformational Leadership”, in: Hickman, Gill Robinson, Editor, Leading Organizations;

Perspectives for a New Era, Sage Publications, London

Diputra \& Rahyuda, 2015, Pengaruh Kepemimpinan Transformasional dan Kepuasan Kerja Terhadap Komitmen organisasi dan Organizational Citizenship Bwhavior Guru SD Saraswati 4 Denpasar, E-Jurnal Manajemen Unud, Vol 4, No. 4

Gibson, J.L., Ivancevich, J.M., Donnelly Jr. 2009. Organisasi: Perilaku, Struktur, Proses, Edisi Bahasa Indonesia, Tangerang: Binarupa Aksara.

Griffith, J. 2004. Relation of principal transformational leadership to school staff job satisfaction, staff turnover, and school performance, Journal of Educational Administration, Vol 42, No 3, pp. 333-356.

Handoko, T.H., 2009, Manajemen Personalia dan Sumber Daya Manusia, Edisi 2, BPFE Yogyakarta

Jahangir, N., Akbar, M., and Haq, M. 2004. Organizational Citizenship Behaviors: Its Nature and Antecedents, BRAC University Journal, Vol I, No 2, pp. 75- 85.

Kartono, Mahadiyanto, \& Mardi, 2015, Mediate Job Satisfaction : Effect of Transformasional Leadership on Organizational Citizenship Behavior (Ocb) (Studies on employees PD. Rural Banks (BPR) in CirebonInternational Conference nad Economic Banking(ICEB-15), Atlantis Press Kompas, 6 Oktober 2009

Lian, L.K., and Tui, L.G. 2012. Leadership Styles and Organizational Citizenship Behavior: The Mediating Effect of Subordinates" Competence and Downward Influence Tactics, Journal of Applied Business and Economics, Vol 13, No 2, pp. 59-96.

Luthans, F, 2006, Perilaku Organisasi, Edisi 10, Penerbit ANDi Yogyakarta

MacKenzie, S.B., Podsakoff, P.M., and Ahearne, M. 1998. Some Possible Antecedents and Consequences of In-Role and Extra-Role Salesperson Performance. The Journal of Marketing, Vol 62, No 3, pp. 87-98.

Maulida, E., Maisaroh,2014, Hubungan antara Kepemimpinan Transformasional dan Komitmen Organisasi pada Karyawan PT Bank Syariah Mandiri Pusat, Proceeding SKN FE UNJ

Munawaroh. 2011. Pengaruh Kepemimpinan Transformasional dan Transaksional Terhadap Kinerja Guru. Jurnal Ekonomi bisnis. Vol. 16 (2). Munawaroh. 2011. Pengaruh Kepemimpinan Transformasional dan Transaksional Terhadap Kinerja Guru. Jurnal Ekonomi bisnis. Vol. 16 (2).

Murphy, G., Athanasou, J., and King, N. 2002. Job Satisfaction and Organizational Citizenship Behaviour: A study of Australian Human-Service Professionals, Journal of Managerial Psychology, Vol 17, No 4, pp. 287-297.

Ngadiman, Eliyana, Ratnawati, 2013, Influence of Transformational Leadership and Organization Climate to work Satisfaction,Organization Commitment, and Organization Citizenship Behavior on the Educational Personnal of Sebelas Maret University, Educational Research International, Vol 1, No. 1

Nguni, Sleeger, \& Denessen, 2007, Transformational and Transactional Leadership Effects on Teachers' Job Satidfaction, Organization Commitment, and Organization Citizenship Behavior in Primary School : The Tanzanian Case, School Effectiveness and School Improvement, Vol 17, No 2, p 145-177 
Nguni, S.C., 2005. A Study of the Effects of Transformational Leadership on Teachers" Job Satisfaction, Organizational Commitment and Organizational Citizenship Behaviour in Tanzanian Primary and Secondary Schools, Doctoral thesis, Universiteit Nijmegen.

Organ, D.W., Podsakoff, P.M., and MacKenzie, S.B. 2006. Organizational Citizenship Behavior: Its Nature, Antecedents, and Consequences, SAGE Publications.

Podsakoff, MacKenzie, Moorman, 1990,Transformational Leader Behaviors and Their Effects on Followers, Trust in Leader, Satisfaction, and Organization Citizenship Behavior, Leadership Quarterly, 1(2), 107-142

Robbins, S.P., and Judge, T.A. 2008. Perilaku Organisasi, Edisi Kedua belas, Jakarta: Salemba Empat.

Rosita T, dan Yuniati T, 2016, Pengaruh Kepuasan Kerja Terhadap Kinerja Karyawan Dengan Komitmen Organisasi Sebagai Variable Intervening, Jurnal Ilmu dan Riset Manajemen, Vol 5, No 1

Shweta, J., and Srirang, J. 2010., Determinants of Organizational Citizenship Behavior: A Review of Literature, Journal of Management and Public Policy, Vol 1 No 2, pp. 27-36.

Ulva, 2012,Efektifitas Sertifikasi Terhadap Kinerja Guru di SMP Muhammadiyah 10 Surakarta,Tahun Pelajaran 2011/2012, Thesis, eprints.ums.ac.id

Wijaya, 2005, Kepemimpinan Transformasional di Sekolah Dalam Meningkatkan Outcome Peserta Didik, Jurnal Pendidikan Vol 4.4

Zahari, I., and Shurbagi, A. 2012. The Effect of Organizational Culture and the Relationship between Transformational Leadership and Job Satisfaction in Petroleum Sector of Libya, International Business Research, Vol 5, No 9, pp. 89-97. 